\title{
Transitions in frailty state after kidney transplantation
}

\section{Evelien E. Quint ${ }^{1}$ (D) - Lasse Schopmeyer ${ }^{1}$ (D) - Louise B.D. Banning ${ }^{1}$ (D) Cyril Moers $^{1}$ (D) $\cdot$ Mostafa El Moumni $^{1}$ (D) Gertrude J. Nieuwenhuijs-Moeke ${ }^{2}$ (D) $\cdot$ Stefan P. Berger ${ }^{3}$ (D) $\cdot$ Stephan J.L. Bakker ${ }^{3}$ (D) $\cdot$ Robert A. Pol $^{1}$ (D)}

Received: 2 April 2020 / Accepted: 10 July 2020 / Published online: 20 July 2020

(C) The Author(s) 2020

\begin{abstract}
Purpose Frailty is the body's failure to return to homeostasis after every day or acute stressful events, causing adverse outcomes. To study its dynamics in kidney transplant recipients (KTR), we determined whether the degree of frailty and its domains are affected by kidney transplantation (KT).

Methods Between 2015 and 2017, 176 KTR were included. Frailty scores were measured using the Groningen Frailty Indicator (GFI), assessed preoperatively and during follow-up. Transitions in frailty state and changes in the individual domains were determined.

Results Mean age $( \pm \mathrm{SD})$ was $51.8( \pm 14.1)$ years, and $63.1 \%$ of KTR were male. Thirty patients were considered frail $(\mathrm{GFI} \geq 4)$ at baseline. After a mean follow-up of $22.8 \pm 8.3$ months, 34 non-frail patients (19.3\%) became frail, 125 patients (71.0\%) remained the same, and 17 frail patients $(9.7 \%)$ became non-frail $(\mathrm{GFI}<4)$. In the domain psychosocial functioning, $28.4 \%$ of the patients had an increase in GFI score after follow-up. Patients who scored a point in the domain cognition at baseline had a greater chance of becoming frail (OR 4.38, 95\% CI 0.59-32.24).

Conclusion In conclusion, almost one-fifth of non-frail KTR transitioned to a frail state after their transplantation. These results could be used to predict the impact of KT on frailty course and help with implementing prehabilitation for patients at risk.
\end{abstract}

Keywords Frailty $\cdot$ Kidney transplantation $\cdot$ Cognition $\cdot$ Mental health

\section{Introduction}

Frailty is a frequently occurring physiological condition in today's aging population. It is the result of aging-associated decline in physical, cognitive, physiological, and immune reserves which leads to a diminished ability to cope with every day or acute stressors [1-3]. Fried et al. [4] have defined frailty as meeting at least three out of five of the following criteria: unintentional loss of weight, low physical activity, exhaustion,

Electronic supplementary material The online version of this article (https://doi.org/10.1007/s00423-020-01936-6) contains supplementary material, which is available to authorized users.

Robert A. Pol

pol.chirurgie@gmail.com

1 Department of Surgery, Division of Vascular and Transplantation Surgery, University Medical Centre Groningen, P.O. Box 30 001, 9700 RB Groningen, The Netherlands

2 Department of Anaesthesiology, University Medical Centre Groningen, Groningen, The Netherlands

3 Department of Internal Medicine, Division of Nephrology, University Medical Centre Groningen, Groningen, the Netherlands low grip strength, and reduced walking speed. An increased inflammatory state, including elevated levels of interleukin 6 and C-reactive protein, has also been reported in frail patients [5]. Next to these physical aspects, limitations in cognitive functioning are an important domain of frailty resulting in unfavorable health outcomes [3].

Preoperatively, approximately one-fifth of kidney transplant recipients (KTR) are considered frail [6]. Frailty in this particular group of patients is associated with an increased risk of immunosuppression intolerance, delayed graft function, and long-term mortality [7-9]. Measuring frailty therefore might aid physicians in the decision to take precautionary measures.

Currently, there are multiple ways to measure frailty [10]. In our center, the Groningen Frailty Indicator (GFI) is used to determine whether a patient is frail or not. The GFI is a multidomain questionnaire focusing not only on the physical aspect of the patient but also on cognitive and psychosocial domains, which is in contrast to many other frailty indicators [11-14]. It consists of 15 items, involving physical, cognitive, psychological, and social aspects of frailty. A GFI $\geq 4$ has previously been demonstrated to be a reliable cut-off value for considering a patient to be frail [15-18]. Unlike other frailty instruments, the GFI proved to be both time and cost efficient, given 
the short time required to complete the test while covering the most important aspects of frailty [19-21].

Current research is mainly focused on the effect of frailty on kidney transplantation (KT) outcomes [7, 9, 16]. Frailty is dynamic, and intervention such as a KT will most likely have an effect on the degree of frailty [22]. Determining changes in frailty is important to gain insight into the course of frailty after surgery and the individual domains that define these changes. By identifying which domains contribute most to a transition in frailty state, an opportunity to build an individualized frailty prevention program is created. The primary aim of this study was to determine transitions in frailty states after KT over a period of 1 to 3 years. Our secondary aim was to assess which domains and/or patient characteristics contributed most to these transitions.

\section{Material and methods}

\section{Study design}

This study was part of a previously published cohort on frailty in KTR at the University Medical Center Groningen (UMCG), the Netherlands [16]. Two hundred and thirtythree patients were prospectively included during the period of 2015 to 2017 . In all patients, the degree of frailty by means of the GFI was measured at admission to the ward prior to kidney transplantation. To determine a transition in frailty state and the individual frailty domains, the questionnaire was obtained a second time by contacting all patients by telephone. In the event that patients were unwilling to discuss this by phone, the questionnaire was sent by conventional mail. A total of 7 patients died during follow-up, and 50 patients were unwilling to participate. One hundred and seventy-six patients (76\%) completed the GFI during follow-up and were included in this study. Due to the descriptive character of this study, our institution's Medical Ethics Committee granted dispensation for the Dutch law regarding patient-based medical research (WMO) obligation (registration no METc2018/050). Patient data were processed and electronically stored according to the declaration of Helsinki - Ethical principles for medical research involving human subjects.

\section{Frailty score and outcome measures}

The GFI consists of 15 questions that cover eight separate domains of functioning: mobility, visual functioning, auditory functioning, nutritional status, comorbidity, cognition, psychosocial functioning, and physical fitness. The GFI questions were answered by the patient with the support of a specially trained nurse. The GFI score was calculated (range 0-15), and patients were considered frail if the outcome resulted in a score $\geq 4$ [23] (Supplemental Table S1). The preoperative score was referred to as the index measurement, and the measurement obtained at follow-up was named the follow-up measurement throughout this study.

The primary outcome measure of this study was the transition in frailty state after kidney transplantation. Patients were stratified into three cohorts consisting of 1 year (maximum 12 months), 2 years (minimum 13 to maximum 24), and 3 years (minimum 25 to maximum 36 months) between index and follow-up measurement. For each patient, it was calculated whether there was no transition in frailty state, a transition from non-frail to frail, or a transition from frail to non-frail after kidney transplantation.

Secondary outcome measures were changes within the individual GFI domains. In addition, if a transition had occurred, we determined which variables were most strongly associated with the transition in frailty state.

\section{Patient data}

Collected data included age (years); sex (male/female); type of kidney donor (living/deceased); type of dialysis prior to transplantation (hemodialysis/peritoneal dialysis/hemodialysis and hemodialysis/pre-emptive); duration of dialysis (months); body mass index (BMI; body mass $(\mathrm{kg}) /$ height $\left.(\mathrm{m})^{2}\right)$; hypertension $(\mathrm{y} / \mathrm{n})$; comorbidities; retransplantation $(\mathrm{y} / \mathrm{n})$; length of hospital stay (days); first warm ischemia time (minutes); cold ischemia time (minutes); second warm ischemia time (minutes); delayed graft function (DGF) (y/n) defined as recipients receiving hemodialysis within the first 7 days after transplantation; intensive care admission $(\mathrm{y} / \mathrm{n})$; readmission within 30 days of KT (y/n); time between KT and follow-up (months); admission between KT and follow-up (y/n); additional surgical procedures between KT and follow-up (y/n); paired exchange $(\mathrm{y} / \mathrm{n})$; and acute rejection $(\mathrm{y} / \mathrm{n})$. Comorbidities were assessed using the Charlson Comorbidity Index. The Charlson Comorbidity Index is a weighted score (0-24), which predicts the 1-year mortality of a patient based on the coexisting medical conditions and age [24]. DGF as well as functional DGF was measured in our cohort. Functional DGF is a more suitable way to measure DGF in living donation transplants. We will refer to DGF in the rest of this paper. Acute rejections and diagnostics were in accordance with the Banff Classification of Renal Allograft Pathology reference guide [25].

\section{Statistical analysis}

For the statistical analysis, the Statistical Package for the Social Sciences (IBM SPSS Statistics for Windows, version 23.0. IBM Corp., Armonk, NY, USA) was used. Categorical variables are presented as numbers and percentages. Continuous variables are presented as mean \pm standard deviation (SD) for normally distributed variables and as median \pm 
interquartile range (IQR) for skewed variables. Distribution was assessed with the help of a Q-Q plot and a histogram.

Differences between continuous variables were tested with an ANOVA test in case of a normal distribution, and the Mann-Whitney $U$ test for a skewed distribution. Differences between categorical variables were assessed using the chi-square test. We analyzed the correlation between transition in frailty state and the before mentioned patient characteristics. We then performed a multivariable analysis using cox regression with non-frail to frail and frail to non-frail as dependent variables. Gender, comorbidities, duration of dialysis, type of kidney donor, and acute rejection were the independent variables in this analysis. These variables were selected based on literature. We also performed a logistic regression with baseline domain measurements as covariates and transition from a non-frail to a frail state as independent. Outcome was adjusted for gender, comorbidities, kidney transplantation type, duration of dialysis, and acute rejection. A $p$ value $\leq 0.05$ was considered to indicate statistical significance. Estimates of the effects were reported with corresponding 95\% confidence intervals.

\section{Results}

\section{Baseline}

Baseline characteristics are presented in Table 1. Mean age of patients was $51.8 \pm 14.1$ years, of which $63.1 \%$ were male. Mean BMI was $26.0 \pm 4.3 \mathrm{~kg} / \mathrm{m}^{2}$. One hundred and four patients $(59.1 \%)$ were dialysis dependent prior to transplantation and $83 \%$ of grafts came from living donors. The mean dialysis duration was $16.7 \pm 21.6$ months. Twenty-five $(14.2 \%)$ patients underwent a retransplantation at the time of inclusion. Twelve $(6.8 \%)$ patients had an acute rejection after kidney transplantation. Mean follow-up time was $22.8 \pm$ 8.3 months. Eighty-two patients $(46.6 \%)$ were readmitted to the hospital at least once during follow-up of this study.

\section{Transition in frailty state}

In total, 34 non-frail patients (19.3\%) became frail, 125 patients $(71.0 \%)$ maintained their baseline frailty status, and 17 frail patients $(9.7 \%)$ became non-frail during follow-up. Twelve non-frail patients $(24.0 \%)$ after 1 year $(N=50), 11$ non-frail patients $(17.7 \%)$ after 2 years $(n=62)$, and 11 non-frail patients $(19.0 \%)$ after 3 years $(n=64)$ became frail. Furthermore, 5 frail patients $(10.0 \%)$ after 1 year $(N=$ 50), 6 frail patients $(9.7 \%)$ after 2 years $(n=62)$, and 6 frail patients $(8.6 \%)$ after 3 years $(n=64)$ became nonfrail (Table 2; Fig. 1).
Table 1 Baseline characteristics

\begin{tabular}{ll}
\hline Parameter & $\begin{array}{l}\text { Number }(\%), \text { mean } \pm \mathrm{SD}^{\mathrm{a}} \\
\text { or median with IQR }\end{array}$ \\
\hline $\begin{array}{l}\text { Number of patients } \\
\text { Age (years) }\end{array}$ & $176(100 \%)$ \\
Sex & $51.8 \pm 14.1$ \\
Male & $111(63.1 \%)$ \\
Female & $65(36.9 \%)$ \\
Type of kidney donor & $146(83.0 \%)$ \\
Living & $30(17.0 \%)$ \\
Deceased & \\
Type of dialysis & $73(41.5 \%)$ \\
Hemodialysis & $29(16.5 \%)$ \\
Peritoneal dialysis & $2(1.1 \%)$ \\
Hemodialysis and peritoneal dialysis & $72(40.9 \%)$ \\
Pre-emptive & $16.7 \pm 21.6$ \\
Duration dialysis (months) & $26.0 \pm 4.3$ \\
BMI ${ }^{\mathrm{c}}$ (kg/m ${ }^{2}$ ) & $98(55.7 \%)$ \\
Hypertension & $3.7 \pm 1.6$ \\
Comorbidities & \\
Retransplantation & $25(14.2 \%)$ \\
predicts the 1-year mortality by measuring \\
(range from 0 to 19)
\end{tabular}

\section{Association between patient characteristics and frailty state}

In Table 3, the patient characteristics associated with different transitions in frailty state are shown. Non-frail patients who transitioned to frail were older $(55.3 \pm 12.7)$ than frail patients who transitioned to non-frail $(51.7 \pm 15.6)$. However, this did 
Table 2 Transition in frailty state

\begin{tabular}{llll}
\hline Frail $^{\text {a }}$ & \multicolumn{2}{l}{ Number (\%) } \\
\hline Preoperative & $30(17.0 \%)$ & \\
Post-operative & $47(26.7 \%)$ & \\
Years of follow-up & Transition in frailty state & \\
& From & To & \\
& & Non-frail & Frail \\
One & Non-frail & $29(58.0 \%)$ & $12(24.0 \%)$ \\
& Frail & $5(10.0 \%)$ & $4(8.0 \%)$ \\
Two & Non-frail & $39(62.9 \%)$ & $11(17.7 \%)$ \\
& Frail & $6(9.7 \%)$ & $6(9.7 \%)$ \\
Three & Non-frail & $44(67.2 \%)$ & $11(19.0 \%)$ \\
& Frail & $6(8.6 \%)$ & $3(5.2 \%)$ \\
Total & Non-frail & $112(63.6 \%)$ & $34(19.3 \%)$ \\
& Frail & $17(9.7 \%)$ & $13(7.4 \%)$ \\
\hline
\end{tabular}

${ }^{a}$ According to the Groningen Frailty Indicator cut-off of $\geq 4$

not reach statistical significance. There was a significant association between paired exchange and transition in frailty state $(p=0.035)$. After multivariable cox regression analysis, no significant associations were found in the risk of transitioning to another frailty state (Table 4).

\section{Change per domain}

The changes in GFI score per domain are shown in Fig. 2 and Supplemental Table S2. In the domains cognition, psychosocial, and physical fitness, $18.8 \%, 28.4 \%$, and $13.1 \%$, respectively, of the patients showed an increase in GFI score. In the domain nutrition, $10 \%$ of the patients showed an increase in GFI score in the 1-year follow-up group. In the 2-year follow-up group and the 3-year followup group, $1.6 \%$ of patients showed an increase in GFI. In the domains mobility and nutrition, $94.9 \%$ and $90.3 \%$, respectively, of patients had no change in GFI score.

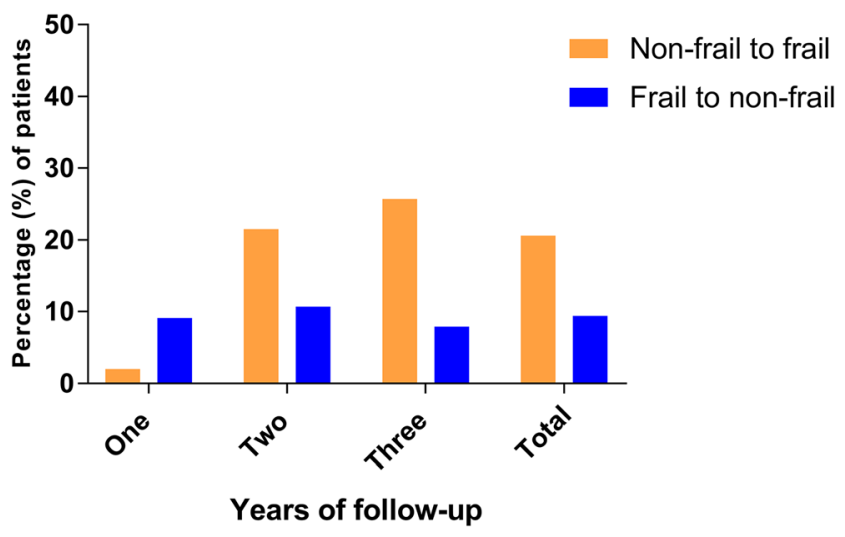

Fig. 1 Transition in frailty state during follow-up

\section{Association between baseline domain score and the transition from a non-frail to a frail state}

In Table 5, the associations between baseline domain score and becoming frail are shown. Patients who scored a point in the domain cognition at baseline had a greater chance of becoming frail (OR 4.38, 95\% CI 0.59-32.24). Patients who scored a point in the domain comorbidity at baseline had a greater chance of becoming frail (OR 1.61, 95\% CI 0.35-7.51).

\section{Discussion}

This study shows the dynamic course of frailty after KT during the first 3 years of follow-up, wherein almost one-fifth of non-frail patients became frail. The frailty domains cognition and psychosocial functioning seem to be the main contributors to this transition. Though there were transitions in frailty state, there was no significant association with outcomes such as delayed graft function or the number of hospital readmissions.

Our results highlight the importance and advantage of including a broad range of domains when measuring frailty. Frailty is multifactorial, and it is necessary to be aware of all the factors that can lead to an increase in frailty to focus on mitigation efforts. Even if a patient is not considered frail, the individual components of frailty could lead to adverse outcomes $[10,26]$. The GFI provides a holistic perspective of frailty, including both physical and psychological components as subgroups, which are often missing in other frailty tools, making it more versatile [23].

In our study, a positive baseline cognition score was associated with a 4 times greater chance of becoming frail. This shows the importance of customized intervention, such as prehabilitation, to avoid further decline. The domain psychosocial functioning also contributed to a transition from a nonfrail to frail state. However, this was not shown to be significant in the logistic regression. At baseline, patients are not struggling psychosocially, but rather that they face problems after kidney transplantation.

Until now, studies have mainly looked at the relationship between depressive symptoms, frailty, and kidney transplantation. It was found that having depressive symptoms led to an increased risk of becoming frail after KT [26, 27]. Likewise, cognitive function has only been studied as a component separate from frailty in the kidney transplant population. Recent research showed that frail patients, according to Fried physical frailty phenotype, have an increased cognitive performance (Modified Mini-Mental State Investigation) in the short term following KT but show declines in cognition in the long term [28]. Based on these data, psychosocial and cognitive factors are apparently of little known influence but have a significant impact on frailty and hence deserve extra attention. It is 
Table 3 Patient characteristics associated with a transition in frailty state

\begin{tabular}{|c|c|c|c|c|}
\hline & $\begin{array}{l}\text { Non-frail to frail } \\
N=34\end{array}$ & $\begin{array}{l}\text { No change } \\
N=125\end{array}$ & $\begin{array}{l}\text { Frail to non-frail } \\
N=17\end{array}$ & $P$ value ${ }^{\mathrm{a}}$ \\
\hline Age (years) & $55.3 \pm 12.7$ & $50.9 \pm 14.3$ & $51.7 \pm 15.6$ & 0.227 \\
\hline \multicolumn{5}{|l|}{ Sex } \\
\hline Male & $22(64.7 \%)$ & $80(64.0 \%)$ & $9(52.9 \%)$ & \multirow[t]{2}{*}{0.659} \\
\hline Female & $12(35.3 \%)$ & $45(36.0 \%)$ & $8(47.1 \%)$ & \\
\hline \multicolumn{5}{|l|}{ Type of kidney donor } \\
\hline Deceased & $7(20.6 \%)$ & $22(17.6 \%)$ & $1(5.9 \%)$ & \multirow[t]{2}{*}{0.401} \\
\hline Living & $27(79.4 \%)$ & $103(82.4 \%)$ & $16(94.1 \%)$ & \\
\hline \multicolumn{5}{|l|}{ Type of dialysis } \\
\hline Pre-emptive & $15(44.1 \%)$ & $48(38.4 \%)$ & $9(52.9 \%)$ & \multirow[t]{4}{*}{0.629} \\
\hline Hemodialysis & $15(44.1 \%)$ & $53(42.4 \%)$ & $5(29.4 \%)$ & \\
\hline Peritoneal dialysis & $3(8.8 \%)$ & $23(18.4 \%)$ & $3(17.6 \%)$ & \\
\hline Hemodialysis and peritoneal dialysis & $1(2.9 \%)$ & $1(0.8 \%)$ & $0(0.0 \%)$ & \\
\hline Duration of dialysis (months) & $21.4 \pm 25.9$ & $15.7 \pm 20.1$ & $14.81 \pm 23.3$ & 0.366 \\
\hline $\mathrm{BMI}^{\mathrm{b}}\left(\mathrm{kg} / \mathrm{m}^{2}\right)$ & $25.9 \pm 3.2$ & $26.0 \pm 4.5$ & $25.9 \pm 4.7$ & 0.978 \\
\hline Hypertension & $19(55.9 \%)$ & $68(54.4 \%)$ & $12(70.6 \%)$ & 0.450 \\
\hline Comorbidities $^{\mathrm{c}}$ & $3.9 \pm 1.7$ & $3.5 \pm 1.6$ & $4.1 \pm 1.8$ & 0.282 \\
\hline Retransplantation & $3(8.8 \%)$ & $19(15.3 \%)$ & $3(17.6 \%)$ & 0.579 \\
\hline Paired exchange & $0(0.0 \%)$ & $13(10.4 \%)$ & $1(5.9 \%)$ & 0.035 \\
\hline Length of stay & $10.2 \pm 4.1$ & $10.1 \pm 6.2$ & $9.7 \pm 5.6$ & 0.180 \\
\hline First warm ischemia time (minutes) & $3(2-4)$ & $3(2-4)$ & $3(3-4)$ & 0.710 \\
\hline Cold ischemia time (minutes) & $162.5(153.0-302.0)$ & $162.0(148.5-202.0)$ & $160.0(151.5-188.0)$ & 0.964 \\
\hline Second warm ischemia time (minutes) & $39.2 \pm 10.7$ & $38.7 \pm 11.0$ & $40.8 \pm 12.9$ & 0.771 \\
\hline Delayed graft function & $5(14.7 \%)$ & $14(11.2 \%)$ & $0(0.0 \%)$ & 0.270 \\
\hline Acute rejection & $1(2.9 \%)$ & $11(8.8 \%)$ & $0(0.0 \%)$ & 0.127 \\
\hline Intensive care unit admission & $2(5.9 \%)$ & $6(4.8 \%)$ & $3(17.6 \%)$ & 0.121 \\
\hline Readmission within 30 days of $\mathrm{KT}^{\mathrm{d}}$ & $3(8.8 \%)$ & $14(11.2 \%)$ & $3(17.6 \%)$ & 0.642 \\
\hline Time between KT and follow-up (months) & $22.7 \pm 8.7$ & $23.0 \pm 8.1$ & $22.4 \pm 7.9$ & 0.950 \\
\hline Readmission between KT and follow-up & $16(47.1 \%)$ & $57(45.6 \%)$ & $9(52.9 \%)$ & 0.849 \\
\hline Surgery between KT and follow-up & $8(23.5 \%)$ & $32(25.6 \%)$ & $4(23.5 \%)$ & 0.959 \\
\hline
\end{tabular}

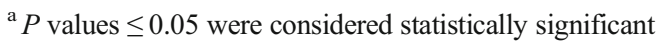

${ }^{\mathrm{b}}$ Body mass index

${ }^{\mathrm{c}}$ According to the Charlson Comorbidity Index, a weighted index which predicts the 1-year mortality by measuring the burden of comorbidities (range from 0 to 19)

${ }^{\mathrm{d}}$ Kidney transplantation

therefore striking that among transplantation health care professionals only $2.2 \%$ believe that psychosocial status is of importance when defining frailty [29]. Additionally, in our center, no program exists to support the psychosocial and cognitive wellbeing of KT candidates. A proactive and preventative measurement should be implemented to combat the negative impact of this domain and increase awareness.
A pilot focusing on prehabilitation among KTR suggested that significant improvement in physical exercise occurs when a preventative program, consisting of physical therapy and athome exercises, is implemented [30]. Furthermore, cognitive training and exercise training have been shown to possibly prevent cognitive decline in hemodialysis patients [31]. Ultimately, creating a patient-tailored post-surgical program
Table 4 Cox regression analysis of factors associated with transition in frailty state

\begin{tabular}{lllll}
\hline Variable & $\begin{array}{l}\text { Non-frail to frail }(n=34) \\
\text { Hazard ratio }(95 \% \mathrm{CI})\end{array}$ & $P$ value & $\begin{array}{l}\text { Frail to non-frail }(n=17) \\
\text { Hazard ratio }(95 \% \mathrm{CI})\end{array}$ & $P$ value $^{\mathrm{a}}$ \\
\hline Gender (female) & $0.94(0.07-3.90)$ & 0.53 & & \\
Comorbidities $(\geq 5$ points) & $0.88(0.39-1.97)$ & 0.75 & $1.86(0.67-5.12)$ & 0.23 \\
Duration dialysis ( $\geq 1$ year) & $1.32(0.62-2.81)$ & 0.46 & $1.40(0.50-3.91)$ & 0.52 \\
Kidney transplantation type & $1.21(0.48-3.04)$ & 0.69 & $5.64(0.65-49.20)$ & 0.12 \\
Acute rejection & $0.53(0.72-3.90)$ & 0.53 & & \\
\hline
\end{tabular}

${ }^{\text {a }} P$ values $\leq 0.05$ were considered statistically significant

${ }^{\mathrm{b}}$ According to the Charlson Comorbidity Index, a weighted index that predicts 1-year mortality by measuring the burden of comorbidities (range 0-19) 


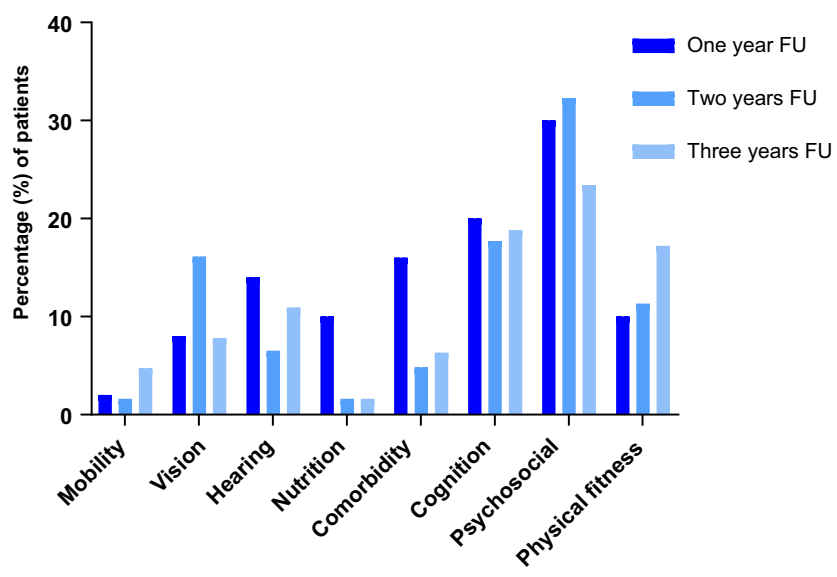

Years of follow-up

Fig. 2 Patients with an increase in GFI score during FU, per domain. GFI, Groningen Frailty Indicator; FU, follow-up

including psychosocial aspects may decrease frailty. This in turn may improve the overall health and wellbeing of the patient and reduce the burden on the healthcare system in the long run. This could have positive financial and capacity effects on a healthcare system that is already under pressure. Prevention and battling against decline in the cognitive and mental health of KTR should become a standard part of transplant care.

Prior studies have shown that there are numerous factors which contribute to becoming frail. In this study, we found

Table 5 The effect of the individual frailty domains at baseline on the transition from a non-frail to a frail state

\begin{tabular}{|c|c|}
\hline Frailty domain & $\begin{array}{l}\text { Non-frail to frail }(n=34) \\
\text { Odds ratio }(95 \% \mathrm{CI})\end{array}$ \\
\hline $\begin{array}{l}\text { Mobility } \\
\text { Mobility }^{\Omega}\end{array}$ & $\begin{array}{l}0.00(0.00-0.00) \\
0.00(0.00-0.00)\end{array}$ \\
\hline $\begin{array}{l}\text { Vision } \\
\text { Vision }^{\Omega}\end{array}$ & $\begin{array}{l}0.33(0.04-2.62) \\
0.34(0.04-2.82)\end{array}$ \\
\hline $\begin{array}{l}\text { Hearing } \\
\text { Hearing }^{\Omega}\end{array}$ & $\begin{array}{l}0.51(0.06-4.20) \\
0.54(0.06-4.70)\end{array}$ \\
\hline $\begin{array}{l}\text { Nutrition } \\
\text { Nutrition }\end{array}$ & $\begin{array}{l}0.92(0.19-4.48) \\
1.10(0.21-5.34)\end{array}$ \\
\hline $\begin{array}{l}\text { Comorbidity } \\
\text { Comorbidity }^{\Omega}\end{array}$ & $\begin{array}{l}1.61(0.35-7.51) \\
1.50(0.30-7.02)\end{array}$ \\
\hline $\begin{array}{l}\text { Cognition } \\
\text { Cognition }^{\Omega}\end{array}$ & $\begin{array}{l}4.38(0.59-32.24) \\
3.44(0.43-27.34)\end{array}$ \\
\hline $\begin{array}{l}\text { Psychosocial } \\
\text { Psychosocial }^{\Omega}\end{array}$ & $\begin{array}{l}0.79(0.32-1.98) \\
0.74(0.29-1.88)\end{array}$ \\
\hline $\begin{array}{l}\text { Physical fitness } \\
\text { Physical fitness } \Omega\end{array}$ & $\begin{array}{l}0.67(0.31-1.43) \\
0.72(0.33-1.60)\end{array}$ \\
\hline
\end{tabular}

${ }^{\text {a }} P$ values $\leq 0.05$ were considered statistically significant

${ }^{\Omega}$ Outcomes adjusted for gender, comorbidities, kidney transplantation type, duration of dialysis, and acute rejection that patients who transitioned from a non-frail state to a frail state were older than patients who transitioned from a frail state to a non-frail state. When people are older at baseline, the likelihood of being/becoming frail increases with the corresponding risk of becoming more frail while aging in general $[1,22,32]$. All patients have end-stage renal disease (ESRD) and the majority requires dialysis, which in itself is associated with an increased risk of being frail [33]. More than one-third of patients with ESRD is frail [34]. Patients with advanced chronic kidney disease often have a low energy intake and are less active than healthy controls. Additionally, there is an increased inflammatory state caused by elevated levels of proinflammatory cytokines in chronic kidney disease [35]. The frailty trajectory among this group of patients is, however, extremely variable with almost the same number of patients improving as deteriorating in frailty score [36]. In the case of kidney transplantation, patients undergo a major surgical procedure associated with a disruption of the vital homeostasis from which the body has to recover. Furthermore, the body has to adapt to the new immunosuppressive drug regimen. These factors increase the risk for a kidney transplant recipient to become more frail over time, compared with communitydwelling older adults who do not endure these changes.

Almost half of the patients which transitioned from a nonfrail to a frail state were pre-emptively transplanted. One would expect pre-emptive patients to be less at risk of becoming frail, given that dialysis can have a great impact on frailty [33]. Prior to transplantation, many pre-emptive patients do not feel ill, though they are living with end-stage kidney disease. After receiving a transplant, they are faced with new problems like infections, complications, stress, and sometimes guilt, all adding to the risk of becoming frail or creating a sense of vulnerability which negatively affects psychosocial and cognitive wellbeing. In contrast, dialysis patients often already experience these issues before the transplantation. Post-transplantation, they do not experience major changes or improve in psychosocial state now that they have a functioning kidney [37]. These changes and effects are currently underexposed in the majority of the kidney transplant programs, including ours. More attention is necessary, including the implementation of a possible intervention.

Interestingly, a part of our population of KTR seemed to improve in frailty (frail to non-frail state) during follow-up. Despite the enormous impact that a KT has on the physical and cognitive reserves of a recipient, the health benefit compared with dialysis or end-stage renal disease is extensive. Herein lies the crux, since a proper patient selection can play an important role in the expected outcome. Which patient will have maximum benefit from a transplant and which will subsequently be hindered by an increase in frailty causing him or her to no longer function at the pre-transplant level? These issues are difficult to answer but must continue to receive attention in view of the increasing aging of the population. 
This study has some limitations that need to be addressed. First, contacting the patient by phone creates a risk of bias. There is a risk that patients do not give all the correct information because an immediate response is required and face to face contact is missing. Also, patients may feel ashamed to report psychological and physical problems or restrictions. To minimize this risk, patients were given sufficient time to think about their answers and if they were not willing to give a response by phone, they received the questionnaire by mail and were offered a follow-up telephone consultation. Our response rate, using this approach, was $75.5 \%$ which is in accordance with other survey studies and resulted in a reliable selection to perform our analyses [38-41]. Second, the GFI is a self-reported questionnaire. Because of differing personalities, pain thresholds, and several coping strategies, a variation in reporting can occur, leading to an under- or overestimation. However, we focused on a transition in frailty within the individual and not on a static frailty measurement. Third, the GFI has not been used as an evaluative measurement instrument until now, only as a screening instrument. The GFI is a widely used, validated screening instrument among various patient categories and can, by its compact and simple design, be filled in by the patient in a relatively short amount of time while covering many aspects of frailty. Fourth, 25 patients had undergone a retransplantation during follow-up which could have clouded the effect of KT on frailty transition. However, the degree of transition in this group was comparable to the entire cohort. The domain psychosocial functioning contributed most to this increase in the retransplantation group. Fifth, measuring frailty at fixed time points and measurements during acute events would have provided a more detailed analysis of transitions in frailty. However, we believe that this study still accurately represents transitions in frailty state that occur during follow-up.

\section{Conclusion}

In conclusion, almost one-fifth of the non-frail kidney transplant patients transitioned to a frail state during the follow-up period of 1 to 3 years after transplantation. Cognitive functioning and psychosocial wellbeing were particularly affected and thereby contributed the most to a transition in becoming frail. Prevention and battling against the decline of the cognitive and mental health of KTR should become a standard part of transplant care. By preoperatively identifying patients at risk of becoming more frail after transplantation, health care providers might be given a tool to decide which specific prehabilitation program and post-surgical therapy could be most beneficial in improving long-term patient and graft outcome.
Authors' contributions Evelien E. Quint: acquired the data, was involved in data analysis and interpretation and drafting the manuscript, and contributed to critical revision of the manuscript. Lasse Schopmeyer: was involved in data analysis and interpretation and contributed to critical revision of the manuscript. Louise B.D. Banning: was involved in data analysis and interpretation and contributed to critical revision of the manuscript. Cyril Moers: contributed to critical revision of the manuscript. Mostafa El Moumni: was involved in data analysis and contributed to critical revision of the manuscript. Gertrude J. Nieuwenhuijs-Moeke: contributed to critical revision of the manuscript. Stefan P. Berger: contributed to critical revision of the manuscript. Stephan J.L. Bakker: contributed to critical revision of the manuscript. Robert A. Pol: conceived the study and its design, acquired the data, and contributed to critical revision of the manuscript.

Funding information This research received no specific grant from any funding agency in the public, commercial, or not-for-profit sectors.

Data availability The datasets generated during and/or analyzed during the current study are available from the corresponding author on reasonable request.

\section{Compliance with ethical standards}

Conflict of interest The authors declare they have no conflict of interest.

Research involving human participants All procedures performed in studies involving human participants were in accordance with the ethical standards of the institutional and/or national research committee and with the 1964 Helsinki declaration and its later amendments or comparable ethical standards.

Informed consent Informed consent was obtained from all individual participants included in the study.

Open Access This article is licensed under a Creative Commons Attribution 4.0 International License, which permits use, sharing, adaptation, distribution and reproduction in any medium or format, as long as you give appropriate credit to the original author(s) and the source, provide a link to the Creative Commons licence, and indicate if changes were made. The images or other third party material in this article are included in the article's Creative Commons licence, unless indicated otherwise in a credit line to the material. If material is not included in the article's Creative Commons licence and your intended use is not permitted by statutory regulation or exceeds the permitted use, you will need to obtain permission directly from the copyright holder. To view a copy of this licence, visit http://creativecommons.org/licenses/by/4.0/.

\section{References}

1. Clegg A, Young J, Iliffe S, Rikkert MO, Rockwood K (2013) Frailty in elderly people. Lancet 381:752-762

2. Xue QL (2011) The frailty syndrome: definition and natural history. Clin Geriatr Med 27:1-15

3. Panza F, Solfrizzi V, Frisardi V, Maggi S, Sancarlo D, Addante F, D'Onofrio G, Seripa D, Pilotto A (2011) Different models of frailty in predementia and dementia syndromes. J Nutr Health Aging 15: 711-719

4. Fried LP, Tangen CM, Walston J et al (2001) Frailty in older adults: evidence for a phenotype. J Gerontol A Biol Sci Med Sci 56:146-156 
5. De Martinis M, Franceschi C, Monti D, Ginaldi L (2006) Inflammation markers predicting frailty and mortality in the elderly. Exp Mol Pathol 80:219-227

6. McAdams-DeMarco MA, Isaacs K, Darko L et al (2015) Changes in frailty after kidney transplantation. J Am Geriatr Soc 63:21522157

7. Garonzik-Wang J, Govindan P, Grinnan JW, Liu M, Ali HM, Chakraborty A, Jain V, Ros RL, James NT, Kucirka LM, Hall EC, Berger JC, Montgomery RA, Desai NM, Dagher NN, Sonnenday CJ, Englesbe MJ, Makary MA, Walston JD, Segev DL (2012) Frailty and delayed graft function in kidney transplant recipients. Arch Surg 147:190-193

8. McAdams-DeMarco M, Law A, Tan J et al (2015) Frailty, mycophenolate reduction, and graft loss in kidney transplant recipients. Transplantation 99:805-810

9. McAdams-DeMarco MA, Law A, King E et al (2014) Frailty and mortality in kidney transplant recipients. Am J Transplant 15:149-154

10. Banning LBD, Visser L, Pol RA (2019) The many faces of frailty in vascular surgery. Eur J Vasc Endovasc Surg 57:892-893

11. Drubbel I, Bleijenberg N, Kranenburg G et al (2013) Identifying frailty: do the Frailty Index and Groningen Frailty Indicator cover different clinical perspectives? A cross-sectional study. BMC Fam Pract 14:64

12. Haugen $\mathrm{C}, \mathrm{Chu} \mathrm{N}$, Ying $\mathrm{H}$ et al (2019) Frailty and access to kidney transplantation. Clin J Am Soc Nephrol 14:576-582

13. Pérez Fernández M, Martínez Miguel P, Ying H, Haugen CE, Chu NM, Rodríguez Puyol DM, Rodríguez-Mañas L, Norman SP, Walston JD, Segev DL, McAdams-DeMarco MA (2019) Comorbidity, frailty, and waitlist mortality among kidney transplant candidates of all ages. Am J Nephrol 49:103-110

14. McAdams-DeMarco M, Olorundare I, Ying H et al (2018) Frailty and postkidney transplant health-related quality of life. Transplantation 102:291-299

15. Pol RA, van Leeuwen BL, Visser L, Izaks GJ, van den Dungen JJAM, Tielliu IFJ, Zeebregts CJ (2011) Standardised frailty indicator as predictor for postoperative delirium after vascular surgery: a prospective cohort study. Eur J Vasc Endovasc Surg 42:824-830

16. Schopmeyer L, El Moumni M, Nieuwenhuijs-Moeke G, Berger S, Bakker S, Pol R (2018) Frailty has a significant influence on postoperative complications after kidney transplantation-a prospective study on short-term outcomes. Transpl Int 32:66-74

17. Drudi LM, Adea M, Mancini R et al (2019) Frailty assessment in older adults undergoing interventions for peripheral arterial disease. J Vasc Surg 70:1594-1602.e1

18. van Loon IN, Goto NA, Boereboom FTJ, Bots ML, Verhaar MC, Hamaker ME (2017) Frailty screening tools for elderly patients incident to dialysis. Clin J Am Soc Nephrol 12:1480-1488

19. Hubbard RE, O'Mahony MS, Woodhouse KW (2009) Characterising frailty in the clinical setting-a comparison of different approaches. Age Ageing 38:115-119

20. Dent E, Kowal P, Hoogendijk EO (2016) Frailty measurement in research and clinical practice: a review. Eur J of Intern Med 31:3-10

21. Buta B, Walston J, Godino J et al (2016) Frailty assessment instruments: systematic characterization of the uses and contexts of highly-cited instruments. Ageing Res Rev 26:53-61

22. Lee J, Auyeung T, Leung J, Kwok T, Woo J (2014) Transitions in frailty states among community-living older adults and their associated factors. J Am Med Dir Assoc 15:281-286

23. Steverink N, Slaets J, Schuurmans H, Van Lis M (2001) Measuring frailty: developing and testing the GFI (Groningen Frailty Indicator). Gerontologist 10:236

24. Charlson ME, Pompei P, Ales KL, MacKenzie CR (1987) A new method of classifying prognostic comorbidity in longitudinal studies: development and validation. J Chronic Dis 40:373-383
25. Roufosse C, Simmonds N, Clahsen-van Groningen M, Haas M, Henriksen KJ, Horsfield C, Loupy A, Mengel M, PerkowskaPtasińska A, Rabant M, Racusen LC, Solez K, Becker JU (2018) A 2018 reference guide to the Banff Classification of Renal Allograft Pathology. Transplantation 102:1795-1814

26. McAdams-DeMarco M, Ying H, Olorundare I et al (2017) Individual frailty components and mortality in kidney transplant recipients. Transplantation 101:2126-2132

27. Konel JM, Warsame F, Ying H, Haugen CE, Mountford A, Chu NM, Crews DC, Desai NM, Garonzik-Wang JM, Walston JD, Norman SP, Segev DL, McAdams-DeMarco MA (2018) Depressive symptoms, frailty and adverse outcomes among kidney transplant recipients. Clin Transpl 32:e13391

28. Chu NM, Gross AL, Shaffer AA, Haugen CE, Norman SP, Xue QL, Sharrett AR, Carlson MC, Bandeen-Roche K, Segev DL, McAdamsDeMarco MA (2019) Frailty and changes in cognitive function after kidney transplantation. J Am Soc Nephrol 30:336-345

29. Kobashigawa J, Dadhania D, Bhorade S et al (2018) Report from the American Society of Transplantation on frailty in solid organ transplantation. Am J Transplant 19:984-994

30. McAdams-DeMarco M, Ying H, Van Pilsum RS et al (2019) Prehabilitation prior to kidney transplantation: results from a pilot study. Clin Transpl 33:e13450

31. McAdams-DeMarco M, Konel J, Warsame F et al (2017) Intradialytic cognitive and exercise training may preserve cognitive function. Kid Int Rep 3:81-88

32. Mitnitski AB, Graham JE, Mogilner AJ, Rockwood K (2002) Frailty, fitness and late-life mortality in relation to chronological and biological age. BMC Geriatr 2:1

33. Chowdhury R, Peel N, Krosch M, Hubbard R (2017) Frailty and chronic kidney disease: a systematic review. Arch Gerontol Geriatr 68:135-142

34. Drost D, Kalf A, Vogtlander N, van Munster B (2016) High prevalence of frailty in end-stage renal disease. Int Urol Nephrol 48: $1357-1362$

35. Nixon AC, Bampouras TM, Pendleton N, Woywodt A, Mitra S, Dhaygude A (2018) Frailty and chronic kidney disease: current evidence and continuing uncertainties. Clin Kidney J 1:236-245

36. Johansen K, Dalrymple L, Delgado C et al (2017) Factors associated with frailty and its trajectory among patients on hemodialysis. Clin J Am Soc Nephrol 12:1100-1108

37. Lai YL, Neo HLM, Vathsala A, Griva K (2020) Comparing emotional adjustment of living-donor and deceased-donor kidney transplant patients. Transplant Direct 6:529

38. Ayres A, Chen R, Mackle T, Ballard E, Patterson S, Bruxner G, Kothari A (2019) Engagement with perinatal mental health services: a cross-sectional questionnaire survey. BMC Pregnancy Childbirth 19:170

39. Sommerer C, Estelmann S, Metzendorf N, Leuschner M, Zeier M (2018) Gender disparity in health-related quality of life and fatigue after living renal donation. BMC Nephrol 19:377

40. Azawi N, Tesfalem H, Dahl C, Lund L (2014) Do the different types of renal surgery impact the quality of life in the postoperative period? Int Urol Nephrol 47:263-269

41. Cheng XS, Lentine KL, Koraishy FM, Myers J, Tan JC (2019) Implications of frailty for peritransplant outcomes in kidney transplant recipients. Curr Transplant Rep 6:16-25

Publisher's note Springer Nature remains neutral with regard to jurisdictional claims in published maps and institutional affiliations. 